\title{
Innovative Methods of Strengthening the Construction Quality of Mechanical and Electrical Engineering
}

\author{
Xianghui Zhang', Weiming $\mathrm{Ji}^{2}$, Yan $\mathrm{Qi}^{3}$, Liguang $\mathrm{Li}^{4}$, Mazhi Shi ${ }^{5}$ \\ ${ }^{1}$ Zhongyuan University of Technology, Shijiazhuang, Hebei Province, 050000 \\ ${ }^{2}$ North China Electric Power University, Shijiazhuang, Hebei Province, 050000 \\ ${ }^{3}$ Hebei Medical University, Shijiazhuang, Hebei Province, 050000 \\ ${ }^{4}$ Hebei Normal University of Science and Technology, Hebei Province, 050000 \\ ${ }^{5}$ Qiqihar University, Shijiazhuang, Hebei Province, 050000
}

\begin{abstract}
With the rapid development of the construction industry, more and more high demands are put on the important modern mechanical and electrical engineering. Many aspects of the mechanical and electrical engineering construction have an impact on the quality of the building. This paper analyzes the principles and methods of construction quality control of electromechanical engineering. In view of the influencing factors of electromechanical construction quality, an innovative method is proposed for reference.
\end{abstract}

Keywords: Mechanical and electrical engineering; construction quality; method innovation

\section{Principles and methods for controlling the construction quality of mechanical and electrical engineering.}

\subsection{Principles of quality control of mechanical and electrical engineering projects.}

As a high-cost investment project, if the electromechanical construction project wants to guarantee the construction quality during construction, it should supervise the quality of the construction process and timely solve its quality problems. As the quality control of the electromechanical construction project has a direct relationship with the quality of the whole electromechanical engineering, the principles that should be followed in monitoring the quality are as follows ${ }^{[1]}$ : (1) The quality problem, as the main problem of the electromechanical construction project, should be taken seriously by relevant departments. In the process of building electromechanical projects need to achieve the objectives of investment, progress and quality objectives, the quality of the most important goal, so only the quality of protection, will increase the efficiency of investment, and thus make the progress of the goal successfully completed; (2) the quality of people Control of the core, because the staff throughout the mechanical and electrical construction projects in the overall construction of the staff control is critical, so in the construction of mechanical and electrical projects, managers should be strengthened, construction and technical personnel to strengthen control so that their sense of responsibility and (3) All employees should abide by the relevant occupational norms, all participants of the project should take the professional norms as the basic principle, carry out the construction in a scientific and objective manner, and ensure that the construction quality of the mechanical and electrical engineering construction projects is further protected. And accurate data for the work of the guidelines; (4) adhere to the principle of prevention, due to the electromechanical project has a higher investment costs, coupled with its irreversible construction process, the quality of its construction in ad-

\footnotetext{
Copyright (C) 2018 Xianghui Zhang et al.

doi: $10.18063 /$ scr.v2i1.391

This is an open-access article distributed under the terms of the Creative Commons Attribution Unported License

(http://creativecommons.org/licenses/by-nc/4.0/), which permits unrestricted use, distribution, and reproduction in any medium, provided the original work is properly cited.
} 
vance control is important Meaning, so in the mechanical and electrical engineering construction process, should Hold the principle of prevention, preventive measures.

\subsection{Methods for quality control of mechanical and electrical engineering projects.}

The quality control of electromechanical project construction includes many methods, including general technical methods, management techniques and methods, and experimental methods. Among them, the management techniques mainly include optimization method, icon method, inspection and acceptance method, mathematical statistics method, PDCA method and multi-unit control method Etc., while the multi-unit control law includes the self-control of the project department, the control of the regulatory unit, the enterprise control, the quality supervision station control, the design unit and the owner control and other standard methods.

\section{Factors affecting the construction quality of mechanical and electrical engineering.}

\subsection{The lack of normative operation of the construction process.}

Electrical and mechanical construction process, the construction process has strict requirements, the need for all aspects of the installation and operation are strictly in accordance with the operation sequence and process, but the rapid development of the construction industry inevitably exist in accordance with the relevant process specifications for construction operations Therefore, the construction equipment should attach great importance to equipment hoisting and other issues to promote the effective construction of mechanical and electrical engineering, so that machinery and equipment play a maximum role. Another non-standard construction operation flow as the current main drawbacks, the incorrect installation sequence will bring greater difficulty in the maintenance of construction equipment, thus affecting the construction quality of mechanical and electrical engineering.

\section{2 the mechanical and electrical engineering construction materials are not qualified.}

Construction material quality of eligibility is the basis of construction so as to protect the quality, but in actual construction process, some construction unit and no detailed knowledge of related materials to choose later, only according to their wishes to purchase the required materials, lead to do not conform to the requirements of the construction of frequent, large influence on the quality of construction;

The other part of the construction unit in mechanical and electrical engineering construction, in order to save the cost, at the time of purchase construction material is not according to requirements, so as to choose the standard and quality is not qualified construction materials, even use some exaggerated false materials, have bigger influence on the mechanical and electrical engineering construction quality.

\subsection{Relatively poor overall quality of construction workers.}

In the actual construction process of mechanical and electrical engineering, construction unit personnel are not fully aware of the importance of their work due to the different levels of comprehensive quality, low level of knowledge, different work experience and relatively poor quality consciousness, More attention to income, and in the construction process is often a certain amount of luck on the quality control of the heart, the normal transfer of the project and orderly have a greater impact; other relevant management personnel in the project construction process, not in accordance with the actual situation is reasonable The assignment of construction tasks, the various aspects of the project can not properly handle and effectively coordinate the construction of the technical level and lack of quality due attention should be given, so the construction quality of mechanical and electrical engineering caused greater constraints.

\subsection{Construction drawings are not accurate enough.}

According to the current mechanical and electrical engineering requirements of the relevant regulations, 
construction should strictly follow the construction drawings for construction, construction drawings design is a more important part of the construction before, and now many mechanical and electrical construction units are mostly used for lightning lightning receptors ${ }^{[2]}$, these The operation must be based on accurate construction drawings, so in the process of designing the construction drawings, attention should be paid to the connection points and the embedded parts. If the accuracy of these standards is ignored during construction, The quality and its accuracy have a significant impact. In the actual construction of mechanical and electrical engineering, construction drawings often do not clearly marked the situation, so the need for mechanical and electrical construction to strengthen its supervision and management.

\subsection{Construction design program is not perfect.}

Because the effective construction design can make the construction quality get a certain protection, so any construction project before the need to design and construction program, but also more and more attention by the construction unit. However, due to the constraints of the construction site environment and construction period and other factors, the construction design schemes often appear unreasonable in size, the construction scale does not conform to the actual construction scale and does not conform to the actual situation, so that in the actual construction process, Appear honeycomb, crack and other quality problems.

\subsection{Lack of scientific and effective management measures.}

According to the relevant construction quality requirements, the construction management should be strictly controlled in the construction of electromechanical projects, so the supervision units are required to strictly control their construction and quality. However, in the actual construction process, the inspection and supervision of many supervision units Without concrete implementation, mechanical and electrical engineering can not be effectively managed, and its quality control has a certain impact, which led to a series of problems, such as not in accordance with the order of irrigation water, not according to the relevant thickness standards for irrigation, concrete mixing Temperature control is not good, pouring time is unreasonable, etc., and then increase the mechanical and electrical construction safety hazards, the construction quality of its greater impact.

\section{Innovative ways to enhance the quality of electromechanical construction.}

\section{1 in strict accordance with the relevant norms process construction.}

If you want to effectively solve the problems in the construction of electromechanical installation, you should formulate the construction plan according to the specific circumstances and carry out the construction strictly in accordance with the relevant construction schemes and processes. In addition, the relevant management personnel should pay attention to the professional knowledge of the electromechanical equipment installation and construction personnel And technical training, mechanical and electrical equipment installation staff skills have been fundamentally improved. In addition to strict construction in accordance with the construction process, it should be in-depth study and analysis of the construction related needs, and in accordance with the specific construction of the appropriate choice of mechanical and electrical equipment, and to develop a scientific installation plan, and the strict implementation of these plans in In the actual construction process,

Whether the management or construction personnel are not free to change the relevant construction and installation plan, the other should not be due to any reason there is any contraction of the construction period, the construction of timely and targeted measures to solve the problem to protect the installation of mechanical and electrical equipment construction The process of strict construction in accordance with relevant norms, so that the quality of the installation of mechanical and electrical equipment has been further improved.

\subsection{To further control the quality of materials and equipment.}


In order to ensure the quality of construction materials and equipment, we should strengthen its supervision and strict management. In the process of purchasing materials and equipment, should be the quality of their purchase for the principle of conformity, and in accordance with the relevant standards require the purchase, not because of cost savings and unauthorized changes to purchase requirements and standards, etc .; completed after the purchase should also be strict Check and control the quality of purchased materials and equipment, clear the details of materials and equipment, such as the production date, manufacturer, size, model, performance, material, grade, etc ${ }^{[3]}$., and do a good job related records; Of the parts of the inspection, and through repeated tests to make it further comply with the relevant construction requirements; In addition, attention should also be paid to the maintenance of materials and equipment maintenance, maintenance through regular inspection found the problems and promptly resolved.

\subsection{Reasonable control of the overall quality of construction workers.}

In the quality control section of mechanical and electrical engineering construction, human factors occupy a major position, so in the specific construction process, the technical quality, quality awareness and practical experience of the construction workers can be reasonably controlled. According to relevant requirements, the employees Knowledge and technology, the quality of the strict checks in detail for the new construction technology staff to explain the electrical and mechanical knowledge and norms to continuously improve its quality and safety awareness, and in strict accordance with the relevant requirements of mechanical and electrical engineering self-test and mutual inspection . In addition, managers should also be strengthened, and managers must be selected in accordance with relevant state regulations. Based on their attitudes and sense of responsibility, they form a unified management body and strictly implement the relevant management system so that the enthusiasm of staff members can be improved. In the effective implementation of the project to make real progress; should also be severely punished in accordance with relevant regulations do not follow the requirements of construction personnel, as far as possible to avoid the impact of human factors, so that works can be carried out smoothly; before construction should also be The construction program for a detailed interview, do a good job related to the record, so that construction workers can have a detailed understanding of the construction of the key points.

\subsection{Further standard drawings requirements.}

Construction drawings as an important basis for the project, its accuracy and normativity is very important, so designers should designate the construction staff instructions, prohibit unauthorized changes during the construction drawings, construction drawings as the standard basis for the actual situation of the project If there is indeed a need to adjust and change the drawings, it should contact the professional design team to confirm the changes of the project, the quality of construction drawings to determine a reasonable, so that the construction quality is guaranteed, so the standard construction drawings seriously affect the progress of the project, Is an important part of the smooth progress of the project.

\subsection{Carefully adjust the preparation of construction design.}

In the design process of electromechanical construction plan, we should fully consider the site construction environment, such as building materials, structures, in order to adjust the construction program; in the design of construction plans, the strength and blending of cement residue Of the coefficient of fly ash accurate calculation to avoid temperature cracks; in order to ensure the smooth construction, before the formal construction should also be joint professionals to promptly solve the design of construction programs, so that the construction quality of electromechanical projects be protected ${ }^{[4]}$.

\subsection{Strengthen the construction management of mechanical and electrical engineering.}

First of all, attention should be paid to the installation of the base ring, and the quality of the base ring should be strictly controlled. The installation process should be tested repeatedly to make it more standard and standardized in installation so as to ensure the construction quality. In addition, infrastructure management should be strengthened. 
Facilities are the key link of the project. Therefore, the quality and the smooth progress of the project and the construction quality are directly related. Therefore, the construction personnel are required to strictly carry out the foundation pouring according to the construction standards and the order so that the quality of the pouring construction and the quality of the electromechanical construction Protection.

Conclusion

In short, the construction quality of electrical and mechanical engineering and construction and mechanical and electrical engineering has a direct relationship, so want to make the construction quality has been improved, we need to constantly innovate the construction quality of electrical and mechanical engineering, to achieve efficient control of its construction quality and further promote the electrical and mechanical Engineering development.

\section{References}

1. Jianxiong Wang. Innovation of Mechanical and Electrical Engineering Construction Quality Innovation [J]. Low Carbon Property 2016; 2 (09).

2. Weijian Zheng. On the improvement of mechanical and electrical engineering construction quality innovation [J]. Jiangxi Building Materials 2015; 6 (11): 71.

3. Jia Hu. Innovative Research on Methods of Improving Construction Quality of Electrical and Mechanical Engineering [J]. Construction Engineering Technology and Design 2016; (12).

4. Junjie Yin. Methods to strengthen the construction quality of mechanical and electrical engineering innovation [J]. China Hi-tech Enterprise 2016; (04): 182-183. 